\title{
A case-control study of the effect of environmental sanitation on diarrhoea morbidity in Malawi.
}

\author{
BEVERLY YOUNG AND JOHN BRISCOE \\ From the Department of Environmental Sciences and Engineering, University of North Carolina, Chapel Hill, \\ NC 27514, USA.
}

SUMMARY A case-control design has been applied in the evaluation of improved environmental sanitation on diarrhoeal diseases in rural Malawi. The study demonstrates the feasibility of using such an approach to evaluate two levels of water supply and sanitation service quickly and at moderate cost. Sample sizes would need to be increased substantially to evaluate multiple levels of service or to investigate interactions between water supply and sanitation. The results indicate that children living in families who use good quality water supplies and latrines experience $20 \%$ less diarrhoea as reported to the health clinics during the warm, rainy season.

Diarrhoeal diseases are a major problem in developing countries, being a leading cause of illness and death in young children. ${ }^{1}$ Using 1980 population estimates, diarrhoea accounts for about 800 million episodes of acute illness and nearly 5 million deaths annually in Africa, Asia (excluding China), and Latin America. ${ }^{2}$ Children under 2 years of age are especially vulnerable, the highest diarrhoeal mortality rates being found in infants and 1-year-olds, and the highest morbidity rates in children 6-11 months of age. ${ }^{2}$ Environmental interventions, including water supply and excreta disposal improvements, have been advocated by the World Health Organization as part of a multifaceted strategy for diarrhoea control. ${ }^{3}$ Considering results of past studies, estimated reductions of $35-50 \%$ in diarrhoea morbidity have been forecast for well-designed projects combining water supply, excreta disposal, and hygiene education. ${ }^{4}$

Many studies on the health effects of improved water supplies and excreta disposal facilities have methodological problems which cast doubt on the validity of their conclusions. Blum and Feacham ${ }^{5}$ cite eight of these problems which include study design, validity of information, and analytical issues. They draw attention to the need for studies on existing water supply and sanitation programmes which are functioning satisfactorily and properly used. Recently, arguments have been presented for applying a casecontrol study design to diarrhoeal impact evaluations of environmental interventions in order to overcome many of these methodological problems. ${ }^{6} \mathrm{~A}$ casecontrol study would allow a more rapid evaluation of environmental projects than prospective studies and require a much smaller sample size than other designs if the disease of interest occurs infrequently among the population. Additionally, such a study could be initiated after the improved system has been shown to be functioning adequately and used appropriately. These potential advantages could result in substantial time and cost savings, but field trials are necessary to evaluate the feasibility of this approach. This paper addresses the application of a case-control design to study the association between diarrhoea (reported to health clinics) in children under 5 years of age and improvements in water supply and sanitation in Malawi.

\section{Materials and methods}

STUDY LOCATION AND POPULATION

The rural eastern Zomba district in Malawi was the area of recruitment for this case-control study. The tropical climate has a marked rainy season from November to March which coincides with peak diarrhoea incidence in young children. About half of the inhabitants are subsistence farmers growing maize or rice; the other half earn outside income through fishing, farming or small businesses. The scattered small villages are dominated by houses built of mud or sun-dried bricks. Several tribes predominate in this region but cultural and behavioural differences are negligible.

Approximately $40 \%$ of the population is served by a gravity-fed piped water system supplied by untreated mountain streams. The system has been operational 
since 1981 and serves around 200 inhabitants at each standpost. These rural piped water systems are based on self-help community development and have a high degree of acceptance and use. The rural piped water project has a counterpart health education and sanitation programme in those villages served by standposts. Other water supplies in this region consist of older boreholes, unprotected surface wells, and streams and rivers.

Diarrhoeal diseases rank as the third highest cause of morbidity and the fifth highest cause of mortality in children under 5 years of age in Malawi according to outpatient health facility and hospital data. ${ }^{7}$ Prevalence has been estimated at $10 \%$ in a similar rural community during the rainy season. ${ }^{8}$ Diarrhoeal diseases increase in frequency beginning in September and peak in January-March during the rainy season.

\section{STUDY DESIGN AND DATA COLLECTION}

Cases and controls were selected at one government and two private health clinics between January and May 1985. All children under 5 years of age reporting to a clinic with diarrhoea and no other symptoms were chosen as cases. Symptomatic diagnoses were made by a project nurse who classified severe diarrhoea by dehydration and four or more loose stools per day or by blood and mucus in the stool. Those children reporting three or less loose stools per day were classified as mild diarrhoea cases.

Controls were randomly selected from children under 5 reporting to the clinic with symptoms of malaria, respiratory illness, whooping cough or measles who did not have severe diarrhoea. Fifty percent of the controls had malaria and another $45 \%$ had respiratory illness. Cases and controls were matched on clinic of recruitment and time of diagnosis. Time matching created incidence-density sampling which obviates the need for assumptions about the exposed proportion and disease rarity when estimating the incidence-density ratio. ${ }^{9}$

The sample size was calculated to detect a $33 \%$ reduction in diarrhoeal morbidity (odds ratio $=0.67$ ) at a $5 \%$ one-sided significance level and a power of $90 \%$. A sample of 460 cases and 460 controls would thus be sufficient to evaluate the protective effect of a single dichotomous exposure if $40-70 \%$ of the population are "exposed" to the environmental improvements. A total of 399 cases and 440 controls were selected at the clinics and $95 \%$ of those had follow-up interviews in the home. Clinical and demographic data and anthropometric measurements were collected by the project nurse and an assistant at the clinics. In the last month of the project, stool samples and rectal swabs were collected at the clinic from a small random sample of both cases and controls for diarrhoeal pathogen isolation studies. The follow-up home interviews were conducted by trained female enumerators who collected data on environmental and socioeconomic conditions. Observations and questions administered to the mothers of the children provided information on water sources, uses and quantity of water, excreta disposal (existence and condition of a latrine), education, and economic indicators (occupation, house construction). Sets of samples of household drinking water and the water sources were randomly collected for $34 \%$ of the respondents at the time of the household interview.

\section{LABORA TORY ANALYSES}

Laboratory analysis of the water samples identified the presence and concentration of fecal coliform organisms. Analyses were performed within 4 hours of sample collection using the membrane filtration technique with Millipore field testing kits and incubators. ${ }^{10}$

STATISTICAL ANALYSIS

Two exposure categories were created based on the improved or unimproved status of the water supply and excreta disposal facilities. Children whose families used both an improved water supply and a latrine were categorised as "exposed to good environmental sanitation"; all other children were considered to be "not exposed". Since diarrhoeal diseases have many known risk factors other than water and sanitation, these were included is potential confounders in the specification of the logistic regression model. The confounders included were age, child feeding practices, water quantity (per capita), mother's education, economic status, and level of health education. Dichotomous response variables were used to represent all categories of confounders except for age and water quantity which were treated as continuous variables. Since controls were matched to cases on the basis of clinic and time of recruitment, and both of these were exposure related but not disease related, clinic and time of recruitment were treated as selection confounders. ${ }^{11}$ Both piped water availability and access to latrines varied during the four months of recruitment since heavy flooding caused pipeline breaks and destruction of the mud-walled latrines. House-to-clinic distance was also controlled to eliminate bias due to an association between distance and water service and the difference in the distances that cases and controls lived from the clinic. ${ }^{6}$

The odds ratio estimate from the logistic regression analysis was used to adjust for confounding variables. The matched odds ratio estimate, using categorical matching on time of exposure, is a consistent estimator of the incidence density ratio (IDR). ${ }^{9}$ Regression coefficients were fitted by maximum likelihood 
estimation, and $95 \%$ confidence intervals around the IDR estimates were calculated using the method given by Kleinbaum, Kupper and Morgenstern. ${ }^{12}$

Anthropometric data were analysed with reference to the recommended NCHS population. ${ }^{13}$ These data were not included in the logistic regression model, however, since nutritional status is an intervening variable in the causal pathway being investigated. Inclusion of such a variable would lead to a biased odds ratio. ${ }^{12} 14$

\section{Results}

CHARACTERISTICS OF STUDY POPULATION

Cases and controls were similar with respect to age, sex, breastfeeding practices, and severity of disease as judged by duration of symptoms prior to the clinic visit (table 1). Ten percent more controls than cases were aged $0-5$ months, but this was balanced by $10 \%$ more cases in the 6-11 month age group. Eighty-seven percent of the children were under 2 years of age. The anthropometric indices showed more current malnutrition among the diarrhoea cases than controls: $15 \%$ of cases compared to $10 \%$ of controls were less than two standard deviations below the median weight for height of the reference population. Long term malnutrition (as measured by height for age) was similar for cases and controls. Case and control families had similar occupations and tribal associations. A slightly higher level of the mother's education and more frequent presence of a family latrine were evident among control families.

Case families more frequently used improved water sources than controls, by 42 to $38 \%$. Quantity of water used in the homes of diarrhoea cases averaged $31 \mathrm{l} / \mathrm{capita} /$ day (lcd), while it was $32 \mathrm{lcd}$ for control families. Due to the abundance and convenience of unprotected water sources during the rainy season, quantity used varied little between improved and unimproved water sources.

\section{WATER QUALITY}

Water quality, as judged by the fecal coliform count, was significantly better in the piped water supply and boreholes than in the unprotected wells, rivers, and streams (table 2). The fecal coliform counts for the improved water supplies, standposts, and boreholes averaged less than 50 colonies $/ 100 \mathrm{ml}$ whereas the unprotected sources generally had fecal coliform levels above 500 colonies $/ 100 \mathrm{ml}$.

The quality of water in the household was primarily a function of quality at the source. An analysis of variance was performed to assess the effect on household water quality (logarithmic values of fecal coliforms) of: water source, where the water jar was stored, whether the jar was covered, whether the
Table 1 Distribution of selected variables in cases and controls.

\begin{tabular}{|c|c|c|}
\hline & $\begin{array}{l}\text { Cases } \\
(n=379) \\
\%\end{array}$ & $\begin{array}{l}\text { Controls } \\
(n=421) \\
\%\end{array}$ \\
\hline \multicolumn{3}{|l|}{ Child's age (months:) } \\
\hline $0-5$ & 20 & 30 \\
\hline 6-11 & 35 & 25 \\
\hline $12-17$ & 22 & 19 \\
\hline $18-23$ & 11 & 12 \\
\hline$<=24$ & 12 & 14 \\
\hline \multicolumn{3}{|l|}{ Child's sex: } \\
\hline Male & 54 & 49 \\
\hline Female & 46 & 51 \\
\hline \multicolumn{3}{|l|}{ Child feeding: } \\
\hline Unsupplemented breastfeeding & 4 & 7 \\
\hline Supplemented breastfeeding & 77 & 74 \\
\hline No breastfeeding & 19 & 19 \\
\hline \multicolumn{3}{|l|}{ Duration of disease symptoms: } \\
\hline One day & 30 & 31 \\
\hline One week & 64 & 64 \\
\hline Up to one month & 5 & 3 \\
\hline$<$ One month & 1 & 2 \\
\hline \multicolumn{3}{|l|}{ Nutrition indicators: } \\
\hline Weight for height, $<-2$ SD & 15 & 10 \\
\hline Height for age, $<-2$ SD & 31 & 31 \\
\hline \multicolumn{3}{|l|}{ Occupation of household head: } \\
\hline Subsistence farmer & so & 49 \\
\hline Commercial farmer & 10 & 10 \\
\hline Businessman & 20 & 19 \\
\hline Fisherman & 5 & 3 \\
\hline Other & 15 & 19 \\
\hline \multicolumn{3}{|l|}{ Mother's education: } \\
\hline None & 57 & 53 \\
\hline Standard 1-4 & 28 & 26 \\
\hline Standard 5-8 & 15 & 18 \\
\hline Form 1-2 & $<1$ & 3 \\
\hline \multicolumn{3}{|l|}{ Family tribe: } \\
\hline Lomwe & 46 & 47 \\
\hline Nyanja, Chewa & 39 & 34 \\
\hline Yao & 13 & 16 \\
\hline Other & 2 & 3 \\
\hline Family latrine & 46 & 49 \\
\hline Use improved water source & 42 & .38 \\
\hline
\end{tabular}

Table 2 Bacteriological water quality.

\begin{tabular}{llll}
\hline Sample location & & $\begin{array}{l}\text { Number of } \\
\text { samples }\end{array}$ & $\begin{array}{l}\text { Fecal coliform } \\
\text { Colonies/100m/* }\end{array}$ \\
\hline Piped water & Source & 107 & 12 \\
& House & 104 & 16 \\
Borehole & Source & 20 & 46 \\
& House & 20 & 240 \\
Unprotected & & & \\
wells \& rivers & Source & 146 & 540 \\
& House & 147 & 760 \\
\hline
\end{tabular}

- Geometric mean 
dipping cup had a handle, and whether the same or a different jar was used for fetching and storing water. The only statistically significant association with household water quality was the source of the water $(p<0.01)$. The lack of association for the storage variables may be because there was little variation in water collection and storage habits in this area, most women storing water in their homes, covering the jar, and using a cup with a handle. Based upon these results, users of piped water or boreholes were considered to use improved water, and users of unprotected sources were considered to use water of inferior quality.

\section{HEALTH EFFECTS OF ENVIRONMENTAL} INTER VENTIONS

Children whose families used both an improved water supply and a latrine were categorised as "exposed to good environmental sanitation"; all other children were considered to be "not exposed". The effect of improved environmental sanitation on the risk of diarrhoeal disease was estimated through crude and multivariate logistic regression analyses. Table 3 presents the results of the crude analysis with reference to those children with only one or no environmental improvements. Improved sanitation appears to reduce diarrhoeal incidence, with an odds ratio estimate of $0.77\left(\chi^{2}=2.09, \mathrm{p}=0.15\right)$.

Since diarrhoea has many other risk factors, however, this crude result was possibly a biased estimate of the true effect. The results of the logistic regression analysis controlling for the confounders listed earlier are shown in table 4 . The effect of the confounding variables can be seen in a similar

Table 3 Crude odds ratio.

\begin{tabular}{lcccc}
\hline & Cases & Controls & $O R$ & $95 \% \mathrm{CI}$ \\
\hline $\begin{array}{l}\text { Without both improved } \\
\text { water and excreta } \\
\text { disposal }\end{array}$ & 311 & 329 & 1.00 & - \\
$\begin{array}{l}\text { With both improved } \\
\text { water and excreta } \\
\text { disposal }\end{array}$ & 68 & 93 & 0.77 & $0.54-1.09$ \\
\hline
\end{tabular}

Table 4 Adjusted ratio controlling for confounders.

\begin{tabular}{lcccc}
\hline & Cases & Controls & OR & $95 \%$ CI \\
\hline $\begin{array}{l}\text { Without both improved } \\
\text { water and excreta } \\
\text { disposal }\end{array}$ & 308 & 327 & 1.00 & - \\
$\begin{array}{l}\text { With both improved } \\
\text { water and excreta } \\
\text { disposal }\end{array}$ & 68 & 92 & 0.80 & $0.54-1.17$ \\
\hline
\end{tabular}

protective effect of improved sanitation with an odds ratio of 0.80 .

The analyses were repeated with a more restrictive set of disease criteria. All diarrhoea cases with mild diarrhoea $(n=28)$ and controls with mild diarrhoea associated with their malaria or respiratory illness $(n=13)$ were excluded. Very similar results were obtained, OR estimates generally being the same. There were no clear indications of possible bias either towards or away from the null with the broader disease classifications. Again, there was a trend towards decreased diarrhoea with the availability of multiple rather than solitary or no interventions.

Further investigations of the data for the individual effects of water supply and excreta disposal yielded no meaningful results. Explorations of other effect modifiers, such as child feeding practices which have been shown to interact with water and sanitation, ${ }^{15}$ were not pursued due to the limitations of the sample size (only $6 \%$ of the children were exclusively breastfed).

\section{Discussion}

This case-control study was conducted to test: (1) the hypothesis that improved environmental sanitation would reduce diarrhoeal incidence; and (2) the feasibility of using a case-control design to evaluate health impacts of environmental interventions. The results have a bearing on both water and sanitation policy and on the prospects for further application of case-control studies to evaluations of such projects. First, though, several methodological and analytical issues must be taken into consideration when interpreting these results.

\section{BIAS}

Misclassification of disease and exposure are both possible sources of bias in this study. Aetiological results of a limited number of stool samples and rectal swabs $^{16}$ did not support an association between specific diarrhoeal pathogens and our clinical definition of diarrhoea. By limiting the recruited diarrhoea cases to those reporting to the health clinics with diarrhoea as the major complaint, it was hoped to eliminate milder and non-infectious diarrhoeas. If the measure of disease is "diarrhoea due to an enteric pathogen", then misclassification was certainly a problem. Because the misclassification was probably non-differential over exposure categories, the result of such misclassification would be to bias the risk estimates towards the null value. ${ }^{17}$

The exposure classification could also introduce bias since facility use (for standposts and boreholes) and availability (for latrines) were assumed to be measures of environmental improvements which 
would affect young children. Although specific actions of the children could not be observed, the research intent was to investigate the impact on diarrhoea of general facility improvements and reasonable use. All families who truly used an improved water source or latrine would have been classified as doing so since classifications were based on observation of facilities. There were no common water treatment practices to improve the quality of a polluted source. Thus, the sensitivity of both the water source and latrine classifications was high. If bias was introduced through poor specificity of the exposure classifications, it would be non-differential and would again bias estimates towards the null value. If misclassification of either disease or exposure did introduce bias, then the observed trends of decreased diarrhoeal incidence associated with improved environmental sanitation would be underestimated.

\section{PRECISION}

The sample size had been calculated to detect a $33 \%$ reduction in diarrhoeal incidence associated with improved water supplies and excreta disposal, no adjustments in size being made for confounders or interaction effects. Controlling other risk factors as confounders in the analysis should have little effect on sample size requirements (increase of $<15 \%$ ) unless they are strongly associated with either disease or exposure. ${ }^{18}$ However, interaction effects may require the sample size to be increased by a factor of four given a single dichotomous effect modifier. In this study, there were several interactions which would have been of interest to investigate: the interactions between water supplies, excreta disposal, and domestic hygiene and the interactions between these environmental interventions and child feeding practices. Obviously the sample size was inadequate for estimating measures of effect for any interactions.

\section{HEALTH POLICY ISSUES}

These data suggest that, for the population who use health clinics, a $20 \%$ decrease in diarrhoea reported to the clinic might be expected during the warm, rainy season for those children under 5 years of age whose families have improved water supplies and excreta disposal. For the area studied, such a decrease would affect approximately $20 \%$ of the population (those with both environmental improvements) using clinics. Comparisons of demographic data on clinic users and the general population show similar characteristics, with a slightly higher status of occupation for clinic users. Hence, such reductions in diarrhoeal incidence might be assumed for the general population during this season.

There is evidence 41920 that, under poor socioeconomic conditions, solitary environmental improvements may be necessary but insufficient for affecting health status. For this reason the Malawi rural water supply project has developed a strong hygiene education and sanitation promotion component. This study shows that where changes in both water supply and sanitation conditions take place there is a substantial reduction in diarrhoeal disease and suggests that this coupling of hardware and software should be continued in Malawi and extended to water supply projects in other countries.

\section{FEASIBILITY OF THE CASE-CONTROL METHODOLOGY}

This study has shown that a case-control design, as presented herein, may effectively be applied to the evaluation of environmental improvements when there is only one dichotomous exposure. If the true effect is near 0.80 rather that the anticipated 0.67 , then the sample size would need to be increased to about 1500 cases and 1500 controls to demonstrate clearly such an association. If interactions between water, excreta disposal, and hygiene are of major interest, as might be the case for many health planners, then sample sizes would be prohibitive for case-control studies (and even greater for prospective or crosssectional studies). The methodological implications of this and a related field test in the Philippines are examined in more detail elsewhere. ${ }^{21}$

This investigation was conducted as part of a research and evaluation programme supported by the US Agency for International Development Mission to the Republic of Malawi. Staff of the Ministry of Health and Ministry of Works Water Department, Government of Malawi, contributed substantially, as did the South African Institute of Medical Research. Special thanks are extended to Dr Moses Chirambo, Dr H J Koornhof, Mr John Lewis, Mr B H Muakikunga, Mr Yohane Nyasulu, and Mr Lindesay Robertson.

\section{References}

${ }^{1}$ Walsh JA, Warren KS. Selective primary health care: an interim strategy for disease control in developing countries. New Eng J Med 1979; 301: 967-74.

2 Snyder JD, Merson MH. The magnitude of the global problem of acute diarrhoeal disease: a review of active surveillance data. Bull WHO 1982; 60: 605-13.

${ }^{3}$ Report of the Sixth Meeting of the Technical Advisory Group, Diarrhoeal Disease Control Group. WHO document, WHO/CDD/85.12, Geneva, 1985.

${ }^{4}$ Esrey SA, Feacham RG, Hughes JM. Interventions for the control of diarrhoeal diseases among young children: improving water supplies and excreta disposal facilities. Bull WHO 1985; 63: 757-72. 
${ }^{5}$ Blum D, Feachem RG. Measuring the impact of water supply and sanitation investments on diarrhoeal diseases: problems of methodology. Int J Epidemiol 1983; 12: 357-65.

${ }^{6}$ Briscoe J, Feachem RG, Rahaman MM. Measuring the impact of water supply and sanitation facilities on diarrhoea morbidity: prospects for case-control methods. WHO document, WHO/CWS/85.3, Geneva, 1985.

${ }^{7}$ Ministry of Health. Control of diarrhoeal diseases. Malawi Epidemiol Quart 1985; 1: 2.

${ }^{8}$ Lindskog P, Lindskog U. Households water supply - a user's or a supplier's problem? Progress Report IV, Linkoping University, Linkoping, Sweden, 1983.

${ }^{9}$ Greenland S, Thomas DC. On the need for the rare disease assumption in case-control studies. Am J Epidemiol 1982; 116: $547-53$.

${ }^{10}$ Lewis WJ, Chilton PJ. Performance of sanitary completion measures of wells and boreholes used for rural water supplies in Malawi. Challenges in African Hydrology and Water Resources, IAHS Publication No. 144, 1984.

${ }^{11}$ Miettinen OS, Cook EF. Confounding: essence and detection. Am J Epidemiol 1981; 114: 593-603.

${ }^{12}$ Kleinbaum DG, Kupper LL, Morgenstern H. Epidemiologic research: principles and quantitative methods. London: Lifetime Learning Publications, 1982: 432-3.

${ }^{13}$ Waterlow JC, Buzzina R, Keller W, Lane JM, Nichaman MZ, Tanner JM. The presentation and use of height and weight data for comparing the nutritional status of groups of children under the age of 10 years. Bull WHO 1977; 55: 489-98.
${ }^{14}$ Schultz TP. Studying the impact of household economic and community variables on child mortality. In: Mosley WH, Chen LC (eds), Child survival strategies for research. Population and Development Review Supplement to Vol 10, 1984: 215-36.

${ }^{15}$ Butz WP, Habicht JP, DaVanzo J. Environmental factors in the relationship between breastfeeding and infant mortality: the role of sanitation and water in Malaysia. Am J Epidemiol. 1984: 119: 516-25.

${ }^{16}$ Young BA, Briscoe J. Water and health in rural Malawi: Aspects of the performance, utilization and health impact of the Malawi Self-Help Rural Water Supply Project. Project Report, Contract CO-612-000-5-50003, USAID/ MALAWI, Lilongwe, 1986.

${ }^{17}$ Bross I. Misclassification in $2 \times 2$ tables. Biometrics 1954; 10: 478-86.

${ }^{18}$ Smith P, Day NE. The design of case-control studies: the influence of confounding and interaction effects. Int $J$ Epidemiol 1984: 13: 356-65.

${ }^{19}$ Shuval HI, Tilden RL, Perry BH, Grosse RN. Effect of investments in water supply and sanitation on health status: a threshold-saturation theory. Bull WHO 1981; 59: 243-8.

${ }^{20}$ Bradley DJ. Towards an engineering view of health. In: Pacey A (ed), Sanitation in developing countries. New York: John Wiley and Sons. 1978: 19-23.

${ }^{21}$ Briscoe J, Baltazar J, Young B. Case-control studies of the effect of environmental sanitation on diarrhoea morbidity: methodological implications of field studies in Africa and Asia. Int J Epidemiol, In press.

Accepted for publication September 1987 